\title{
GEOMATICS AND RESTORATION. CULTURAL HERITAGE: CHALLENGES, NEW PERSPECTIVES AND TECHNOLOGY INNOVATION. TOWARD INFORMATIVE CONTENT MODELS AND BEYOND
}

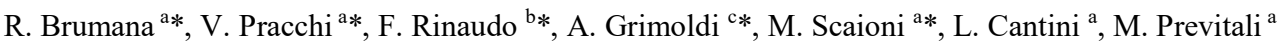 \\ (Editors)
}

\author{
${ }^{a}$ Politecnico di Milano, Department of Architecture, Built Environment and Construction Engineering, Via Ponzio 31, 20133 - \\ (raffaella.brumana, valeria.pracchi, marco.scaioni, lorenzo.cantini, mattia.previtali)@polimi.it \\ ${ }^{\mathrm{b}}$ Politecnico di Torino, Department of Architecture and Design, Viale Mattioli 39, 10129 Torino, Italy - fulvio.rinaudo@polito.it \\ ${ }^{\mathrm{c}}$ Politecnico di Milano, DASTU - Department of Architecture and Urban Studies - alberto.grimoldi@polimi.it;
}

\section{WG II/8, WG III/5,WG IV/II, WG V/I}

\section{PREFACE}

Our publication aims to bring together the communities of Geomatics and Restoration by addressing the critical and potential aspects of the field while tackling digitization and the Digital Cultural Heritage. When innovation and new technologies are applied to preservation policies of Cultural Heritage and real user needs, we can try to obtain more effective solutions to many of the challenges presented to the field of Geomatics and Restoration.

The GEORES2019 conference presents an opportunity for experts from Geomatics and Restoration to exchange ideas and the challenges they face in areas such as Architectural heritage, Archaeology, Built Environment, Heritage Urban Landscape (HUL) in a multi-temporal and multi-scale fluid environment.

Often we grapple with applying technology in an effective manner, dealing with the complexity and unicity of the cultural heritage in the aforementioned disciplines like, surveying methods, data processing, geographic and modelling tools. Technologically proposed solutions must consider if it is economically viable, with an efficient use of time to get reliable interpretations.

Modeling tools represent one of the most exciting technology for our experts as their use can greatly augment work in the field of Geomatics and Restoration. Many challenging subjects have been discussed to this purpose: HBIM need to undertake innovative generative modelling approaches capable to embody the complexity of $\mathrm{CH}$, overcoming the limits of BIM adopted for new constructions; accuracy achieved in the scan-to-HBIM process can play an important role in knowledge acquisition and interpretation, it needs to be merged to all the related Information acquired and addressed to the different requirements during the different phases, addressed to the preservation of the authenticity of materials, structural behaviour and functionalities of the architectural heritage. To this aim we can include within the HBIM a wealth of information ('I') covering historical data, materials, stratigraphic units, construction techniques, arrangements, ancient skilled workers, multi-temporal historical and current maps, documents from archives and collections, technological data, energy data, structural data, seismic data, and Open Data coming from different sources. In particular, semantics and vocabularies can play an important role in the co-relation of information and models across space and time. HBIM single nodes can be related ones to each other by means of semantic based virtual hub platforms capable to connect, discover and access their contents within a holistic approach, generating unexpected pictures and knowledge.

Informative Models and Systems, such as Heritage Building Information Modeling (HBIM) and Geographic Information Systems (GIS/WEBGIS) can be coupled with Virtual Hub platform and application implemented on them representing one of the powerful innovative virtual spaces to search and access all the data acquired. We can construct 4D HBIM-Models integrated by GEO-DB of the Architectural Heritage and its elements (i.e. walls, vaulted systems, trusses) in conjunction with Heritage Urban Landscape (HUL).

Often models and information are destined to be left in the digital drawers after the research analysis and conservation phases. They can be used as 'live' data sources to enrich the content of museums, with the support of the eXtended Reality: they can contribute feeding Virtual Museums in the different forms with an extraordinary richness of contents circulated by the informative models to nonprofessional experts. The usage of eXtended Reality (XR) - Augmented Reality (AR), Virtual Reality (VR), Mixed Reality (MR) - for explaining $\mathrm{CH}$ to wider audiences have enormous potential in information dissemination. An extraordinary opportunity to rising awareness among citizens toward an informed society supported by content based narratives.

* Chairs of the GEORES2019 conference 
The important role of training and capacity building within value chains has been underlined by many contributions. The example of the New Paradigm/New Tools SSHRC internship programme (Social Science and Humanities Research Council), led by the Carleton University (CIMS) and funded by the Canadian Research Council, to which many partners, universities and research centres contribute as co-participants, allowed a fruitful cross-fertilization through the exchange of students (undergraduate, graduates, and $\mathrm{PhD}$ candidates), whose results is part of the GEORES2019 publications.

The conference has been combined with a preliminary Workshop (2019, May 6-7) organized at the Basilica di Sant'Ambrogio (Milan), open to $\mathrm{PhD}$ students, postdoctoral fellows and young researchers. Surveying demonstrations with innovative instruments and hands-on processing sessions have been focused to underline the value of collaboration between geomatics and restorers, to share experiences and points of view on the following subjects: (i) handheld 3D scanner, mobile mapping system (MMS) based on SLAM technology, (ii) Scan-to-HBIM-generative modelling tutorial, (iii) data acquisition and processing with UAVs, (iv) low-cost metric instrument documentation, and (v) thermal images to detect covered structures, brick layering and identify thermal anomalies.

Keynotes and invited lectures have been addressed to discuss the growing of architectural vocabularies, the biography of objects, the challenging potentials of $5 \mathrm{G}$ and devices in the future being, ethics issues in the digital recording for conserving heritage places, EU H2020 Virtual Multimodal Museum (ViMM) Manifesto Road Map and Action Plan for the Horizon-Europe Framework programme, Strategy \& Development on Heritage Urban Landscape.

All the papers here included have been presented at the GEORES2019, the $2^{\text {nd }}$ International Conference on Geomatics and Restoration, "Cultural heritage: challenges, new perspectives and technology innovation. Toward informative content models and beyond" (8-10 May, Milan, Italy) and have been accepted with the peer reviewed extended abstracts by the conference Scientific Committee.

The contributions are related to the topics of the conference and are organized in the following sub-sections and sessions:

- $\quad$ HBIM (LOD, LOI, LOG, LOA, GOG, GOA): Generative Modelling and Accuracy, Object libraries, thematic mapping, data analysis and content enrichment

- $\quad$ HBIM - multi-actors and co-working Common Data Environment

- Monitoring \& Restoration: Built Environment and Infrastructures

- Open standards, ontologies, vocabularies, semantics and Big Data Hubs for Cultural Heritage knowledge

- Interactive content based eXtended Reality (VR/AR/MR), Virtual Museum and devices

- Low-cost sensors and new algorithms in cultural heritage digitization. New tools and training lesson learnt

- Heritage Urban Landscape (HUL). Landscapes and needs of multi-temporal multi-spatial maps data collection (BIM-GIS)

- Archaeology, data analysis, informative models and systems

- Training activities, internship programmes, building capacities and value chain

- Preservation, climate change, hydrogeological, seismic risk and resilience management for Cultural Heritage and Built Environment

- Inclusive cultural heritage sites

GEORES2019 has been the natural prosecution of GEORES2017, the $1^{\text {st }}$ International Conference on "Geomatics and Restoration: Conservation of Cultural Heritage in the Digital Era" (22-24 May, Florence, Italy), chaired by Grazia Tucci, to whom is addressed our gratefulness.

The conference has been organized by Politecnico di Milano (POLIMI), in conjunction with Università degli Studi Firenze (UNIFI) and Politecnico di Torino (POLITO) to boost the value of networking among academies and scientific research centres working at a national and international level on the $\mathrm{DCH}$.

AUTEC (the Academic Association of Topography and Cartography), SIRA (the Academic Association of Architectural Restoration), SIFET (the Italian Society of Photogrammetry and Surveying), which work in different realms of the Cultural Heritage sector, permitted and guarantee the results achieved.

GEORES2019 has been organized as ISPRS and CIPA - the ICOMOS International committee on Heritage Documentation - event, and it has been supported by ISPRS (WG II/8, WG III/5, WG V/I), CIPA, ICOMOS, UNESCO Chair in Digital Cultural Heritage at the Cyprus University of Technology and EU ERA Chair on Digital Cultural Heritage, under the patronage of IGMI (the Italian Geographic Military Institute), and professional organizations of Architects and Engineers. It received sponsorships by the Carleton Immersive Media Studio (Carleton University, Ottawa, Canada), Microgeo Srl, GEOMAX Srl, STONEX® Srl.

As editors of this ISPRS volume, we hope that academics, architects, engineers, geomatics, restorers, decision makers and students interested in Cultural Heritage, will benefit from the GEORES2019 contributions.

We would like to thank all the Authors, the Reviewers, the Honorary Committee, the Scientific Committee and the Organizing Committee for their valuable contribution to this publication.

Milan, May 2019 